\title{
Correlations among two self-report questionnaires for measuring DSM-defined anxiety disorder symptoms in children: the Screen for Child Anxiety Related Emotional Disorders and the Spence Children's Anxiety Scale
}

Citation for published version (APA):

Muris, P. E. H. M., Schmidt, H. G., \& Merckelbach, H. L. G. J. (2000). Correlations among two self-report questionnaires for measuring DSM-defined anxiety disorder symptoms in children: the Screen for Child Anxiety Related Emotional Disorders and the Spence Children's Anxiety Scale. Personality and Individual Differences, 28, 28-28. https://doi.org/10.1016/S0191-8869(99)00102-6

Document status and date:

Published: 01/01/2000

DOI:

10.1016/S0191-8869(99)00102-6

Document Version:

Publisher's PDF, also known as Version of record

Please check the document version of this publication:

- A submitted manuscript is the version of the article upon submission and before peer-review. There can be important differences between the submitted version and the official published version of record. People interested in the research are advised to contact the author for the final version of the publication, or visit the DOI to the publisher's website.

- The final author version and the galley proof are versions of the publication after peer review.

- The final published version features the final layout of the paper including the volume, issue and page numbers.

Link to publication

\footnotetext{
General rights rights.

- You may freely distribute the URL identifying the publication in the public portal. please follow below link for the End User Agreement:

www.umlib.nl/taverne-license

Take down policy

If you believe that this document breaches copyright please contact us at:

repository@maastrichtuniversity.nl

providing details and we will investigate your claim.
}

Copyright and moral rights for the publications made accessible in the public portal are retained by the authors and/or other copyright owners and it is a condition of accessing publications that users recognise and abide by the legal requirements associated with these

- Users may download and print one copy of any publication from the public portal for the purpose of private study or research.

- You may not further distribute the material or use it for any profit-making activity or commercial gain

If the publication is distributed under the terms of Article $25 \mathrm{fa}$ of the Dutch Copyright Act, indicated by the "Taverne" license above,

Download date: 26 Apr. 2023 


\title{
Correlations among two self-report questionnaires for measuring DSM-defined anxiety disorder symptoms in children: the Screen for Child Anxiety Related Emotional Disorders and the Spence Children's Anxiety Scale
}

\author{
Peter Muris*, Henk Schmidt, Harald Merckelbach \\ Department of Psychology, Maastricht University, PO Box 616, 6200 MD, Maastricht, The Netherlands
}

Received 6 November 1998; received in revised form 7 March 1999; accepted 18 March 1999

\begin{abstract}
The Screen for Child Anxiety Related Emotional Disorders (SCARED) and the Spence Children's Anxiety Scale (SCAS) are recently developed self-report questionnaires for measuring DSM-IV defined anxiety disorder symptoms in children. The present study examined correlations among these measures in a large sample of Dutch school children $(N=1011)$. Results showed that there was a strong correlation between the total anxiety scores of these instruments $(r=0.89)$. Furthermore, most of the SCARED subscales were found to be convincingly connected to their SCAS counterparts. Finally, a confirmatory factor analysis revealed that SCARED and SCAS anxiety disorder subscales loaded uniquely on separate but intercorrelated factors (i.e., the DSM-IV anxiety disorder categories). These findings can be taken as evidence for the concurrent validity of the SCARED and the SCAS. Although these measures were developed independently, they seem to measure highly similar constructs, viz anxiety symptoms which can be clustered into the anxiety disorder categories as described in the DSMIV. (C) 1999 Elsevier Science Ltd. All rights reserved.
\end{abstract}

Keywords: Anxiety disorders; Children; Assessment; Screen for Child Anxiety Related Emotional Disorders; Spence Children's Anxiety Scale

\footnotetext{
* Corresponding author. Tel.: +31-43-388-1908; fax: + 31-43-361-5735.

E-mail address: p.muris@psychology.unimaas.nl (P. Muris)
}

0191-8869/99/\$ - see front matter (C) 1999 Elsevier Science Ltd. All rights reserved.

PII: S0191-8869(99)00102-6 


\section{Introduction}

It has long been recognized that symptoms of anxiety and true anxiety disorders are quite common in children and adolescents. Recent epidemiological studies have suggested that between 8 and $12 \%$ of children suffer from some type of anxiety disorder that is sufficiently severe to interfere with daily functioning (see, for comprehensive reviews, Bernstein, Borchardt \& Perwien, 1996; Craske, 1997).

In the past decade, researchers and clinicians have reached consensus on the various types of childhood anxiety disorders (American Academy of Child and Adolescent Psychiatry, 1997). According to the latest edition of the Diagnostic and Statistical Manual of Mental Disorders (i.e., DSM-IV; American Psychiatric Association [APA], 1994) the following anxiety disorders in youths are discernable: (1) separation anxiety disorder is characterized by excessive anxiety concerning separation from the home or from significant attachment figures, to a degree that is beyond the child's developmental level; (2) generalized anxiety disorder, formerly termed overanxious disorder (APA, 1987), refers to excessive anxiety and worry, accompanied by symptoms of motor tension and vigilance; (3) social phobia is concerned with marked and persistent fear of social or performance situations in which embarrassment may occur; (4) panic disorder is characterized by the presence of panic attacks (i.e., a discrete period of intense fear) accompanied by persistent concern about their recurrence or their consequences; (5) obsessive-compulsive disorder is characterized by the occurrence of obsessions, i.e., intrusive ideas, thoughts, images, or impulses that cause marked anxiety or distress, and compulsions, i.e., repetitive behaviours or mental acts which serve to neutralize anxiety; (6) specific phobia is characterized by marked and persistent anxiety provoked by exposure to a specific feared object or situation, often leading to avoidance behaviour; and (7) acute stress disorder and posttraumatic stress disorder are both characterized by the reexperiencing of an extremely traumatic event accompanied by symptoms of increased arousal and by avoidance of stimuli associated with the trauma.

Self-report questionnaires of childhood anxiety represent a time-efficient way to capture information about a wide range of anxiety symptoms. The three most widely used instruments for this purpose are the Revised Children's Manifest Anxiety Scale (RCMAS: Reynolds \& Richmond, 1978), the State-Trait Anxiety Inventory for Children (STAI-C: Spielberger, 1973), and the Fear Survey Schedule for Children-Revised (FSSC-R: Ollendick, 1983). One important shortcoming of these measures is that they are all indices of general anxiety and not keyed to the anxiety disorders listed in the DSM-IV.

The Screen for Child Anxiety Related Emotional Disorders (Birmaher et al., 1997; Muris, Merckelbach, Schmidt \& Mayer, 1999b) and the Spence Children's Anxiety Scale (SCAS: Spence, 1997, 1998) are two recently developed self-report questionnaires that attempt to measure childhood anxiety symptoms in terms of the DSM-IV taxonomy. The questionnaires are not completely identical. The original SCARED developed by Birmaher et al. (1997) measures symptoms of generalized anxiety disorder, separation anxiety disorder, social phobia, panic disorder, and school phobia. Muris et al. (1999b) revised the SCARED by adding items that index obsessive-compulsive disorder, specific phobia (divided into three subtypes: animal phobia, blood-injection-injury phobia, and situational-environmental phobia), and traumatic stress disorder. Thus, the revised SCARED taps symptoms of the entire anxiety disorders 
spectrum listed in the DSM-IV. The SCAS measures the following anxiety disorders: generalized anxiety disorder, separation anxiety disorder, social phobia, panic disorder and agoraphobia, obsessive-compulsive disorder, and specific phobia represented by a subscale named 'physical injury fears'.

Research has provided evidence for the reliability and validity of the SCARED and the SCAS. Both questionnaires seem to be reliable in terms of internal consistency and test-retest stability (Muris et al., 1999b; Muris, Merckelbach, Van Brakel \& Mayer, 1999c; Spence, 1998). Furthermore, support has been found for the concurrent validity of both measures. For example, scores of the SCARED and SCAS correlate strongly with scores on traditional childhood anxiety measures such as the RCMAS, STAIC, and FSSC-R (Muris, Merckelbach, Van Brakel, Mayer \& Van Dongen, 1998a; Muris, Merckelbach, Mayer, Van Brakel, Thissen, Moulaert \& Gadet, 1998b; Spence, 1998). Finally, SCARED and SCAS also seem to possess discriminant validity. More specifically, there is evidence to suggest that SCARED and SCAS satisfactorily discriminate children with a specific anxiety disorder from children without that particular disorder (Birmaher et al., 1997; Spence, 1998).

The main purpose of the present study was to examine the relationship between SCARED and SCAS in a large sample of Dutch school children $(N=1011)$. This was done in two ways. First of all, correlations between the anxiety disorder subscales of both questionnaires were computed. Second, a confirmatory factor analysis was carried out to examine to what extent corresponding SCARED and SCAS subscales load uniquely on latent factors that are in keeping with DSM-IV defined anxiety disorders.

\section{Method}

\subsection{Children}

The sample consisted of 1011 children, 524 boys and 487 girls, from regular primary and secondary schools in South-Limburg, The Netherlands. Children had a mean age of 12.77 years, $\mathrm{SD}=2.48$, range $7-19$. No exact information about the socio-economic background, ethnicity, and family structure of the children was available. On the basis of information provided by the staff of the schools that participated in the present study, the percentages of children with low, middle, and upper socio-economic background were estimated at 15, 60, and $25 \%$, respectively. The vast majority of the children (about $95 \%$ ) were Caucasian, and approximately $5 \%$ of the children came from broken families.

Informed consent was obtained from parents and children before participation in the study. More than $80 \%$ of the parents and the children who were approached to take part in the study agreed to participate. 


\subsection{Questionnaires ${ }^{1}$}

The revised version of the SCARED contains 66 items measuring symptoms of generalized anxiety disorder (13 items; e.g., "I worry about things working out for me"); separation anxiety disorder including school phobia (12 items; e.g., "I don't like being away from my family", "I am scared to go to school"); social phobia (4 items; e.g., "I don't like to be with people I don't know"); panic disorder (13 items; e.g., "When frightened, my heart beats fast"); obsessive-compulsive disorder (9 items; e.g., "I have thoughts that frighten me"); animal phobia ( 3 items; e.g., "I am afraid of an animal that is not really dangerous"); blood-injectioninjury phobia (7 items; e.g., "I am afraid to go to the dentist"); situational-environmental phobia (5 items; e.g., "I am scared to fly in an airplane"). Children have to indicate how frequently they experience each symptom on a 3 -point scale: $0=$ almost never, $1=$ sometimes, $2=$ often. SCARED total anxiety and subscale scores can be obtained by summing across relevant items.

The SCAS consists of 38 items that can be allocated to the following anxiety disorders: generalized anxiety disorder (6 items; e.g., "I worry that something bad will happen"); separation anxiety disorder (6 items; e.g., "I feel scared when I have to sleep on my own"); social phobia (6 items; e.g., "I feel afraid that I will make a fool of myself in front of people"); panic disorder and agoraphobia (9 items; e.g., "All of a sudden I feel really scared for no reason at all", "I feel scared when I have to travel in the car, on a bus or a train"); obsessivecompulsive disorder (6 items; e.g., "I have to think of special thoughts to stop bad things from happening"); and physical injury fears replacing specific phobias (5 items; e.g., "I am scared of dogs"). Items of the SCAS are rated on 4-point scales: never, sometimes, often, or always. These are scored $0,1,2$ and 3, respectively. SCAS total anxiety and subscale scores are computed by summing scores on relevant items.

\subsection{Procedure}

Children completed both questionnaires in their classrooms. The teacher and/or a research assistant was always present to help the children if necessary and to ensure confidential and independent responding.

\subsection{Statistical analysis}

The Statistical Package for Social Sciences (SPSS) was used for computing correlations and carrying out the analyses of variance. For the confirmatory factor analyses, EQS, the structural equations modeling approach (Bentler, 1995) was used. As both SCARED and SCAS data were skewed, unweighted least squares factor extraction was considered to be most appropriate. With EQS, it is possible to test a plausible model that may underlie a data set. The present study tested whether corresponding SCARED and SCAS subscale items, indeed, load on latent factors representing the DSM-IV defined anxiety disorders that the items

\footnotetext{
${ }^{1}$ Dutch translations of SCARED and SCAS were used in the current study.
} 
purport to measure. EQS produces a range of goodness-of-fit indexes ${ }^{2}$ : (1) the Average Absolute Standardized Residuals (AASR; this value should be lower than 0.05); (2) the Normed Fit Index (NFI), Non-Normed Fit Index (NNFI), and Comparative Fit Index (CFI) (these values should be 0.80 or higher for an acceptable fit).

\section{Results}

\subsection{Internal consistency}

The internal consistency of the SCARED total anxiety score turned out to be good: Cronbach's alpha was 0.94. The internal consistency of the SCARED subscales was also acceptable, with alphas of 0.81 for generalized anxiety disorder, 0.75 for separation anxiety disorder, 0.76 for social phobia, 0.81 for panic disorder, 0.66 for obsessive-compulsive disorder, 0.82 for animal phobia, 0.72 for blood-injection-injury phobia, 0.66 for situationalenvironmental phobia, and 0.81 for traumatic stress disorder.

Similar figures were obtained for the SCAS. Cronbach's alphas were 0.92 for the total anxiety score, 0.77 for generalized anxiety disorder, 0.74 for separation anxiety disorder, 0.73 for social phobia, 0.81 for panic disorder and agoraphobia, 0.75 for obsessive-compulsive disorder, and 0.57 for physical injury fears.

\subsection{Factor structure}

Confirmatory factor analyses were carried out on the SCARED and SCAS. These analyses replicated the results of previous studies on the factor structure of these questionnaires (Muris et al., 1999b; Birmaher et al., 1997; Spence, 1998). First, no satisfactory model for the SCARED data was found when all subscales were included in the analyses. Yet additional analyses carried out on parts of the SCARED provided support for the presence of a number of anxiety symptoms clusters. For example, with the 38 original SCARED items, a 5correlated-factors model (with generalized anxiety disorder, separation anxiety disorder, social phobia, panic disorder, and school phobia) provided a reasonable fit for the data: $\mathrm{AASR}=0.04, \mathrm{NFI}=0.78, \mathrm{NNFI}=0.82$, and $\mathrm{CFI}=0.83$. Second, the factor structure of the SCAS was satisfactory. The 6-correlated-factors model provided the best fit for the data: $\mathrm{AASR}=0.04, \mathrm{NFI}=0.79$, NNFI $=0.82$, and $\mathrm{CFI}=0.83$.

\subsection{Age and gender effects}

To examine age and gender differences in SCARED and SCAS anxiety symptoms, a series of 2 (gender) $\times 2$ (age groups: 7-12 year-olds (202 boys and 196 girls), 13-19 year-olds (322 boys and 291 girls)) analyses of variance was carried out. On all SCARED and SCAS scales,

\footnotetext{
2 'Chi square divided by degrees of freedom' was not used in the present study, because this goodness-of-fit index is not appropriate with large sample sizes (Marsh, Balla \& McDonald, 1988).
} 
Table 1

Means, standard deviations (SD), and 10\% cut-off scores by age and gender for each SCARED scale ${ }^{\mathrm{a}}$

\begin{tabular}{|c|c|c|c|c|c|c|c|c|c|c|c|}
\hline \multirow[t]{2}{*}{ SCARED } & & \multicolumn{3}{|c|}{$7-12$ year-olds } & \multicolumn{3}{|c|}{ 13-19 year-olds } & \multicolumn{3}{|c|}{ Total sample } & \multirow{2}{*}{$\begin{array}{l}\text { ANOVA } \\
\text { Effects }\end{array}$} \\
\hline & & Boys & Girls & Total & Boys & Girls & Total & Boys & Girls & Total & \\
\hline \multirow[t]{3}{*}{ Total anxiety score } & $M$ & 37.56 & 46.81 & 42.11 & 29.41 & 39.43 & 34.17 & 32.55 & 42.40 & 37.30 & Age: $F(1,1007)=45.09, P<0.001$ \\
\hline & SD & 19.36 & 19.96 & 20.17 & 16.23 & 17.29 & 17.46 & 17.93 & 18.75 & 18.97 & Gender: $F(1,1007)=69.43, P<0.001$ \\
\hline & Cut off & 64 & 74 & 71 & 48 & 60 & 56 & 56 & 69 & 62 & Age $\times$ gender: $F(1,1007)=0.11, P=0.74$ \\
\hline \multirow[t]{3}{*}{ Generalized anxiety disorder } & $M$ & 5.32 & 6.59 & 5.95 & 5.50 & 7.48 & 6.44 & 5.43 & 7.12 & 6.24 & Age: $F(1,1007)=5.49, P<0.05$ \\
\hline & SD & 3.51 & 3.61 & 3.61 & 3.41 & 3.57 & 3.62 & 3.45 & 3.61 & 3.63 & Gender: $F(1,1007)=51.52, P<0.001$ \\
\hline & Cut off & 11 & 12 & 11 & 10 & 13 & 12 & 10 & 13 & 11 & Age $\times$ gender: $F(1,1007)=2.46, P=0.12$ \\
\hline \multirow[t]{3}{*}{ Separation anxiety disorder } & $M$ & 6.86 & 8.02 & 7.43 & 5.05 & 5.94 & 5.47 & 5.75 & 6.78 & 6.24 & Age: $F(1,1007)=67.66, P<0.001$ \\
\hline & SD & 4.12 & 4.32 & 4.25 & 3.12 & 3.39 & 3.28 & 3.64 & 3.92 & 3.81 & Gender: $F(1,1007)=18.92, P<0.001$ \\
\hline & Cut off & 12 & 15 & 14 & 9 & 10 & 10 & 10 & 12 & 12 & Age $\times$ gender: $F(1,1007)=0.34, P=0.56$ \\
\hline \multirow[t]{3}{*}{ Social phobia } & $M$ & 3.44 & 4.19 & 3.81 & 3.10 & 4.01 & 3.53 & 3.23 & 4.08 & 3.64 & Age: $F(1,1007)=4.13, P<0.05$ \\
\hline & SD & 1.98 & 1.83 & 1.94 & 2.05 & 2.12 & 2.13 & 2.03 & 2.01 & 2.06 & Gender: $F(1,1007)=41.21, P<0.001$ \\
\hline & Cut off & 6 & 7 & 6 & 6 & 7 & 6 & 6 & 7 & 6 & Age $\times$ gender: $F(1,1007)=0.38, P=0.54$ \\
\hline \multirow[t]{3}{*}{ Panic disorder } & $M$ & 4.76 & 6.31 & 5.52 & 3.43 & 4.93 & 4.14 & 3.94 & 5.49 & 4.69 & Age: $F(1,1007)=31.21, P<0.001$ \\
\hline & $\mathrm{SD}$ & 3.74 & 4.28 & 4.08 & 3.12 & 4.04 & 3.66 & 3.43 & 4.19 & 3.89 & Gender: $F(1,007)=39.92, P<0.001$ \\
\hline & Cut off & 10 & 13 & 11 & 7 & 10 & 9 & 8 & 11 & 10 & Age $\times$ gender: $F(1,1007)=0.01, P=0.92$ \\
\hline \multirow[t]{3}{*}{ Obsessive-compulsive disorder } & $M$ & 6.33 & 7.28 & 6.80 & 5.43 & 5.96 & 5.68 & 5.77 & 6.49 & 6.12 & Age: $F(1,1007)=30.82, P<0.001$ \\
\hline & SD & 3.34 & 3.13 & 3.27 & 3.06 & 2.94 & 3.02 & 3.20 & 3.09 & 3.16 & Gender: $F(1,007)=13.88, P<0.001$ \\
\hline & Cut off & 10 & 12 & 11 & 10 & 10 & 10 & 10 & 11 & 10 & Age $\times$ gender: $F(1,1007)=1.11, P=0.29$ \\
\hline \multirow[t]{3}{*}{ Animal phobia } & $M$ & 1.07 & 1.91 & 1.48 & 0.72 & 1.64 & 1.16 & 0.86 & 1.75 & 1.29 & Age: $F(1,1007)=10.12, P<0.001$ \\
\hline & SD & 1.26 & 1.82 & 1.61 & 1.24 & 1.74 & 1.56 & 1.26 & 1.77 & 1.59 & Gender: $F(1,1007)=80.37, P<0.001$ \\
\hline & Cut off & 3 & 5 & 4 & 2 & 4 & 3 & 3 & 4 & 3 & Age $\times$ gender: $F(1,1007)=0.12, P=0.73$ \\
\hline \multirow[t]{3}{*}{ Blood-injection-injury phobia } & $M$ & 4.30 & 5.58 & 4.93 & 3.08 & 4.69 & 3.85 & 3.55 & 5.05 & 4.27 & Age: $F(1,1007)=31.97, P<0.001$ \\
\hline & SD & 2.83 & 3.01 & 2.99 & 2.73 & 3.02 & 2.98 & 2.83 & 3.04 & 3.02 & Gender: $F(1,1007)=59.97, P<0.001$ \\
\hline & Cut off & 8 & 10 & 9 & 7 & 9 & 8 & 8 & 9 & 9 & Age $\times$ gender: $F(1,1007)=0.80, P=0.37$ \\
\hline
\end{tabular}


Table 1 (continued)

\begin{tabular}{|c|c|c|c|c|c|c|c|c|c|c|c|}
\hline \multirow[t]{2}{*}{ SCARED } & & \multicolumn{3}{|c|}{$7-12$ year-olds } & \multicolumn{3}{|c|}{ 13-19 year-olds } & \multicolumn{3}{|c|}{ Total sample } & \multirow{2}{*}{$\begin{array}{l}\text { ANOVA } \\
\text { Effects }\end{array}$} \\
\hline & & Boys & Girls & Total & Boys & Girls & Total & Boys & Girls & Total & \\
\hline \multirow[t]{3}{*}{ Situational-environmental phobia } & $M$ & 2.72 & 3.71 & 3.21 & 1.51 & 2.57 & 2.02 & 1.98 & 3.03 & 2.49 & Age: $F(1,1007)=76.61, P<0.001$ \\
\hline & $\mathrm{SD}$ & 2.20 & 2.36 & 2.33 & 1.64 & 2.09 & 1.94 & 1.96 & 2.27 & 2.18 & Gender: $F(1,1007)=61.27, P<0.001$ \\
\hline & Cut off & 6 & 7 & 7 & 4 & 5 & 5 & 5 & 6 & 5 & Age $\times$ gender: $F(1,1007)=0.06, P=0.81$ \\
\hline \multirow[t]{3}{*}{ Traumatic stress disorder } & $M$ & 2.77 & 3.20 & 2.98 & 1.59 & 2.20 & 1.88 & 2.04 & 2.61 & 2.31 & Age: $F(1,1007)=61.48, P<0.001$ \\
\hline & $\mathrm{SD}$ & 2.26 & 2.43 & 2.35 & 1.90 & 2.16 & 2.05 & 2.12 & 2.32 & 2.24 & Gender: $F(1,1007)=14.27, P<0.001$ \\
\hline & Cut off & 6 & 7 & 6 & 4 & 5 & 5 & 5 & 6 & 6 & Age $\times$ gender: $F(1,1007)=0.40, P=0.53$ \\
\hline
\end{tabular}

${ }^{\text {a }}$ SCARED $=$ Screen for Child Anxiety Related Emotional Disorders; ANOVA = analysis of variance; $10 \%$ cut off scores $=$ scores referring to cutoff for highest percentile. 
Table 2

Means, standard deviations (SD), and 10\% cut-off scores by age and gender for each SCAS scale ${ }^{a}$

\begin{tabular}{|c|c|c|c|c|c|c|c|c|c|c|c|}
\hline \multirow[t]{2}{*}{ SCAS } & & \multicolumn{3}{|c|}{$7-12$ year-olds } & \multicolumn{3}{|c|}{ 13-19 year-olds } & \multicolumn{3}{|c|}{ Total sample } & \multirow{2}{*}{$\begin{array}{l}\text { ANOVA } \\
\text { Effects }\end{array}$} \\
\hline & & Boys & Girls & Total & Boys & Girls & Total & Boys & Girls & Total & \\
\hline \multirow[t]{3}{*}{ Total anxiety score } & $M$ & 17.42 & 23.69 & 20.51 & 13.54 & 19.89 & 16.56 & 15.04 & 21.42 & 18.11 & Age: $F(1,1007)=23.33, P<0.001$ \\
\hline & SD & 13.95 & 13.79 & 14.20 & 10.69 & 11.83 & 11.68 & 12.19 & 12.78 & 12.87 & Gender: $F(1,1007)=63.05, P<0.001$ \\
\hline & Cut off & 37 & 44 & 42 & 25 & 36 & 30 & 28 & 41 & 35 & Age $\times$ gender: $F(1,1007)=0.00, P=0.96$ \\
\hline \multirow[t]{3}{*}{ Generalized anxiety disorder } & $M$ & 3.86 & 5.04 & 4.44 & 3.51 & 4.92 & 4.18 & 3.65 & 4.97 & 4.28 & Age: $F(1,1007)=1.72, P=0.19$ \\
\hline & SD & 2.87 & 2.76 & 2.87 & 2.57 & 2.78 & 2.76 & 2.69 & 2.77 & 2.81 & Gender: $F(1,1007)=54.17, P<0.001$ \\
\hline & Cut off & 8 & 9 & 9 & 6 & 9 & 8 & 7 & 9 & 8 & Age $\times$ gender: $F(1,1007)=0.46, P=0.50$ \\
\hline \multirow[t]{3}{*}{ Separation anxiety disorder } & $M$ & 2.89 & 3.56 & 3.21 & 1.51 & 2.28 & 1.87 & 2.04 & 2.79 & 2.40 & Age: $F(1,1007)=74.12, P<0.001$ \\
\hline & SD & 2.91 & 3.00 & 2.97 & 1.81 & 2.10 & 1.99 & 2.39 & 2.58 & 2.51 & Gender: $F(1,1007)=21.75, P<0.001$ \\
\hline & Cut off & 7 & 8 & 8 & 4 & 5 & 5 & 5 & 6 & 6 & Age $\times$ gender: $F(1,1007)=0.13, P=0.72$ \\
\hline \multirow[t]{3}{*}{ Social phobia } & $M$ & 2.86 & 4.07 & 3.45 & 3.09 & 4.45 & 3.73 & 3.00 & 4.30 & 3.62 & Age: $F(1,1007)=3.10, P=0.08$ \\
\hline & SD & 2.58 & 2.73 & 2.72 & 2.58 & 2.85 & 2.79 & 2.58 & 2.80 & 2.77 & Gender: $F(1,1007)=54.99, P<0.001$ \\
\hline & Cut off & 6 & 8 & 7 & 6 & 8 & 7 & 6 & 8 & 7 & Age $\times$ gender: $F(1,1007)=0.21, P=0.65$ \\
\hline \multirow[t]{3}{*}{ Panic disorder } & $M$ & 2.55 & 3.67 & 3.10 & 1.37 & 2.28 & 1.80 & 1.83 & 2.84 & 2.31 & Age: $F(1,1007)=44.01, P<0.001$ \\
\hline & SD & 3.37 & 3.45 & 3.45 & 2.30 & 3.12 & 2.75 & 2.81 & 3.33 & 3.11 & Gender: $F(1,1007)=27.14, P<0.001$ \\
\hline & Cut off & 6 & 8 & 8 & 4 & 6 & 5 & 5 & 8 & 6 & Age $\times$ gender: $F(1,1007)=0.29, P=0.59$ \\
\hline \multirow[t]{3}{*}{ Obsessive-compulsive disorder } & $M$ & 2.88 & 3.56 & 3.21 & 2.25 & 2.52 & 2.38 & 2.49 & 2.93 & 2.71 & Age: $F(1,1007)=24.48, P<0.001$ \\
\hline & SD & 2.81 & 2.88 & 2.86 & 2.44 & 2.49 & 2.47 & 2.61 & 2.70 & 2.66 & Gender: $F(1,1007)=7.74, P<0.01$ \\
\hline & Cut off & 7 & 7 & 7 & 5 & 6 & 5 & 6 & 7 & 6 & Age $\times$ gender: $F(1,1007)=1.48, P=0.22$ \\
\hline \multirow[t]{3}{*}{ Physical injury fears } & $M$ & 2.37 & 3.81 & 3.08 & 1.81 & 3.44 & 2.59 & 2.03 & 3.59 & 2.78 & Age: $F(1,1007)=10.42, P<0.005$ \\
\hline & SD & 2.23 & 2.43 & 2.44 & 2.04 & 2.30 & 2.32 & 2.13 & 2.36 & 2.37 & Gender: $F(1,1007)=114.07, P<0.001$ \\
\hline & Cut off & 5 & 7 & 7 & 5 & 6 & 6 & 5 & 7 & 6 & Age $\times$ gender: $F(1,1007)=0.45, P=0.50$ \\
\hline
\end{tabular}

${ }^{\mathrm{a}} \mathrm{SCAS}=$ Spence Children's Anxiety Scale; ANOVA $=$ analysis of variance, $10 \%$ cut off scores $=$ scores referring to cut-off for highest percentile. 
Table 3

Correlations (corrected for gender and age) between SCARED and SCAS scales ${ }^{\mathrm{a}}$

\begin{tabular}{|c|c|c|c|c|c|c|c|}
\hline & \multicolumn{7}{|l|}{ SCAS } \\
\hline & $\begin{array}{l}\text { Total } \\
\text { anxiety } \\
\text { score }\end{array}$ & $\begin{array}{l}\text { Generalized } \\
\text { anxiety } \\
\text { disorder }\end{array}$ & $\begin{array}{l}\text { Separation } \\
\text { anxiety } \\
\text { disorder }\end{array}$ & $\begin{array}{l}\text { Social } \\
\text { phobia }\end{array}$ & $\begin{array}{l}\text { Panic } \\
\text { disorder and } \\
\text { agoraphobia }\end{array}$ & $\begin{array}{l}\text { Obsessive } \\
\text { compulsive } \\
\text { disorder }\end{array}$ & $\begin{array}{l}\text { Physical } \\
\text { injury fears }\end{array}$ \\
\hline \multicolumn{8}{|l|}{ SCARED } \\
\hline Total anxiety score & 0.89 & 0.76 & 0.76 & 0.66 & 0.73 & 0.66 & 0.67 \\
\hline Generalized anxiety disorder & $\overline{0.72}$ & $\underline{0.71}$ & 0.51 & 0.70 & 0.70 & 0.55 & 0.44 \\
\hline Separation anxiety disorder & 0.73 & $\overline{0.57}$ & $\underline{0.79}$ & 0.51 & 0.61 & 0.53 & 0.49 \\
\hline Social phobia & 0.50 & 0.44 & $\overline{0.41}$ & $\underline{0.49}$ & 0.37 & 0.28 & 0.47 \\
\hline Panic disorder & 0.77 & 0.69 & 0.60 & $\overline{0.54}$ & $\underline{0.72}$ & 0.56 & 0.50 \\
\hline Obsessive-compulsive disorder & 0.69 & 0.59 & 0.57 & 0.48 & $\overline{0.53}$ & $\underline{0.67}$ & 0.43 \\
\hline Animal phobia & 0.47 & 0.37 & 0.33 & 0.34 & 0.34 & $\overline{0.31}$ & $\underline{0.60}$ \\
\hline Blood-injection-injury phobia & 0.57 & 0.43 & 0.52 & 0.39 & 0.43 & 0.35 & $\overline{0.63}$ \\
\hline Situational-environmental phobia & 0.65 & 0.46 & 0.60 & 0.38 & 0.60 & 0.42 & $\overline{0.68}$ \\
\hline Traumatic stress disorder & 0.60 & 0.53 & 0.51 & 0.36 & 0.54 & 0.52 & $\overline{0.35}$ \\
\hline
\end{tabular}

${ }^{\text {a }}$ SCARED $=$ Screen for Child Anxiety Related Emotional Disorders; SCAS = Spence Children's Anxiety Scale; $N=1011$. All correlations were significant at $P<0.001$. Correlations between SCARED and SCAS scales that are supposed to tap symptoms of the same anxiety disorder are underlined. 
significant effects of gender emerged (e.g., SCARED total anxiety score: $F(1,1007)=69.43$, $P<0.001$; SCAS total anxiety score: $F(1,1007)=63.05, P<0.001)$. In all cases, girls exhibited higher levels of anxiety disorder symptoms than boys. Furthermore, significant age effects were found for most of the scales (e.g., SCARED total anxiety score: $F(1,1007)=45.09, P<0.001$; SCAS total anxiety score: $F(1,1007)=23.33, P<0.001)$. In general, younger children displayed substantially higher SCARED and SCAS scores than older children. Such age effects were less convincing or not found for symptoms of social phobia and generalized anxiety disorder. These symptoms remained relatively stable across both age groups (see Tables 1 and 2). Finally, no significant interaction of gender and age on any of the SCARED and SCAS scales emerged. In order to provide normative data of these questionnaires, mean scores, standard deviations as well as the cut-off score for the top $10 \%$ of the SCARED and SCAS scales are given in the Tables 1 and 2.

\subsection{Correlational analysis}

Table 3 presents correlations (corrected for gender and age) between SCARED and SCAS scales. As can be seen, there was a strong correlation between the total anxiety scores of both scales: $r=0.89, P<0.001$. Furthermore, the correlations between SCARED subscales and their SCAS counterparts were generally substantial. Thus, SCARED generalized anxiety disorder was strongly associated with SCAS generalized anxiety disorder, SCARED separation anxiety disorder with SCAS separation anxiety disorder, and so on. Note also that the correlations between corresponding SCARED and SCAS subscales were greater than the correlations between non-corresponding subscales. There was one exception to this pattern. The correlation between SCARED social phobia and its SCAS counterpart was rather modest $(r=0.49, P<0.001)$. Moreover, SCAS social phobia was more convincingly associated with

Table 4

Confirmatory factor loadings of SCARED and SCAS anxiety disorder scales on predicted 6 factors ${ }^{\mathrm{a}}$

\begin{tabular}{|c|c|c|c|c|c|c|}
\hline & $\mathrm{F} 1$ & $\mathrm{~F} 2$ & F3 & $\mathrm{F} 4$ & F5 & F6 \\
\hline SCARED Generalized anxiety disorder & 0.81 & & & & & \\
\hline SCAS Generalized anxiety disorder & 0.88 & & & & & \\
\hline SCARED Separation anxiety disorder & & 0.89 & & & & \\
\hline SCAS Separation anxiety disorder & & 0.88 & & & & \\
\hline SCARED Social phobia & & & 0.63 & & & \\
\hline SCAS Social phobia & & & 0.82 & & & \\
\hline SCARED Panic disorder & & & & 0.88 & & \\
\hline SCAS Panic disorder and agoraphobia & & & & 0.82 & & \\
\hline SCARED Obsessive-compulsive disorder & & & & & 0.86 & \\
\hline SCAS Obsessive-compulsive disorder & & & & & 0.79 & \\
\hline SCARED Animal phobia & & & & & & 0.53 \\
\hline SCARED Blood-injection-injury phobia & & & & & & 0.73 \\
\hline SCARED Situational-environmental phobia & & & & & & 0.82 \\
\hline SCAS Physical injury fears & & & & & & 0.79 \\
\hline
\end{tabular}

\footnotetext{
${ }^{\text {a }} \mathrm{SCARED}=$ Screen for Child Anxiety Related Emotional Disorders; SCAS = Spence Children's Anxiety Scale.
} 
SCARED generalized anxiety disorder, panic disorder, and separation anxiety disorder than with SCARED social phobia.

\subsection{Confirmatory factor analysis}

The SCARED and the SCAS have 6 anxiety disorder subscales in common: generalized anxiety disorder, separation anxiety disorder, social phobia, panic disorder, obsessivecompulsive disorder, and specific phobia. A confirmatory factor analysis was carried out to test whether each SCARED or SCAS subscale loaded uniquely on the latent factor (anxiety disorder category) that the subscale was hypothesized to represent. However, acknowledging the fact that anxiety disorder categories are positively associated with each other (see Table 3), the factors were allowed to intercorrelate.

Table 4 shows the factor loadings of each SCARED and SCAS anxiety disorder subscale on the hypothesized latent factors. As can be seen, each subscale loaded convincingly on its predicted factor (all loadings $>0.50$ ). Goodness-of-fit indices for this model were: $\mathrm{AASR}=0.03, \mathrm{NFI}=0.93, \mathrm{NNFI}=0.90$, and $\mathrm{CFI}=0.94$, indicating that this model provided an excellent fit to the data.

\section{Discussion}

The present study examined correlations among two self-report questionnaires for measuring DSM-defined childhood anxiety disorder symptoms: the SCARED and the SCAS. Results showed that there was a strong correlation between the total anxiety scores of these instruments $(r=0.89)$. Furthermore, most of the SCARED subscales were found to be convincingly connected to their SCAS counterparts. Finally, a confirmatory factor analysis revealed that SCARED and SCAS anxiety disorder subscales loaded uniquely on separate but intercorrelated factors (anxiety disorder categories). These findings can be taken as evidence for the concurrent validity of the SCARED and the SCAS. Although these measures were developed independently, they seem to measure highly similar constructs, viz, anxiety symptoms which can be clustered into the anxiety disorder categories as described in the DSMIV.

The correlation between the social phobia subscales of both questionnaires was relatively low $(r=0.49)$. Inspection of the item content revealed that both scales seem to measure different features of social anxiety. Whereas the SCARED social phobia scale is concerned with children's fear of meeting unfamiliar people (e.g., "I am shy with people I don't know well"), the SCAS social phobia scale focuses on performance fear (e.g., "I worry that I will do badly at my schoolwork") and fear of negative evaluation (e.g., "I worry what other people think of me"). To examine the relative merits of the SCARED and SCAS social phobia subscales in the measurement of social anxiety, future studies should address the connection between both social phobia scales and specific measures of social phobia such as the Society Anxiety Scale for Children (LaGreca \& Stone, 1993).

The current study provides further support for the psychometric properties of SCARED and SCAS. The internal consistency (Cronbach's alpha) of the total anxiety scores of both 
questionnaires was excellent with acceptable values for the various anxiety disorder subscales. Furthermore, while the factor structure of the SCAS and the original SCARED (Birmaher et al., 1997) appeared to be good, no satisfactory model was found for the complete 66-item SCARED. Apparently, the addition of new items covering symptoms of traumatic stress disorder and several types of specific phobias have detrimental consequences for the structure of this questionnaire.

At a theoretical level, the present data replicate a number of findings that have been previously found in the literature on childhood anxiety. First of all, marked sex differences were found for all SCARED and SCAS scales. This result accords well with earlier research showing that girls generally exhibit higher levels of anxiety disorder symptoms than boys (for a comprehensive review of this topic, see Craske, 1997). Second, significant age effects for most of the anxiety disorder scales. Younger children displayed higher levels of anxiety disorder symptoms than older children. Again, this finding is in agreement with previous studies that found a decline in anxiety symptoms with increasing age (Craske, 1997; Bernstein \& Borchardt, 1991). Third and finally, anxiety disorder categories appeared to be substantially intercorrelated. This result is in keeping with findings of epidemiological studies showing that there is strong comorbity of anxiety disorders in children (Craske, 1997).

The SCARED scores of the present sample compare well with those obtained in previous studies (Muris et al., 1998a,b, 1999b). However, a comparison with the mean SCAS scores of large samples of Australian children reported by Spence $(1997,1998)$ revealed that the present sample displayed relatively low scores on this measure. There is no ready explanation for this finding, but it would be worthwhile to compare SCARED and SCAS scores of children from various countries and to examine the differential levels of anxiety disorders symptomatology in children from different cultures and ethnicity (see, for a discussion of this issue, Ollendick, Yang, King, Dong \& Akande 1996).

In conclusion, then, the SCARED and the SCAS are concurrent self-report questionnaires that both tap symptoms of DSM-IV defined anxiety disorders in children. Which of the two instruments should clinicians and researchers preferably use? The SCAS is shorter than the SCARED (38 vs 66 items, respectively) and its factor structure is more straightforward. More specifically, the factor structure of the revised SCARED is not satisfactory (see also Muris et al., 1999b). On the other hand, this version of the SCARED covers a broader range of the anxiety disorder spectrum. More specifically, the SCARED includes a traumatic stress disorder subscale and thus makes it possible to screen for this type of anxiety symptoms. A recent study by Muris, Merckelbach, Körver \& Meesters (1999a) has provided evidence for the validity of this subscale: children who scored high on the traumatic stress disorder scale reported to have experienced more 'traumatic' life events and had higher scores on concurrent posttraumatic stress disorder questionnaires (e.g., the Impact of Event Scale: Horowitz, Wilner \& Alvarez, 1979) than children who scored low on this scale. Furthermore, the SCARED discriminates between three types of specific phobias. Keeping in mind that specific phobias are one of the most prevalent anxiety problems in children and that each type of specific childhood phobia has its typical symptoms that require different therapeutical interventions, a self-report scale that is able to differentiate between various childhood phobias is certainly valuable (see also Muris, Schmidt \& Merckelbach, 1999d). Thus, whereas the SCAS is a psychometrically sound instrument that should be preferred in research studies, the SCARED provides additional and 
more detailed information as to children's anxiety disorders symptoms and therefore might be more valuable to clinical practice.

\section{References}

American Academy of Child Adolescent Psychiatry (1997). Practice parameters for the assessment and treatment of children and adolescents with anxiety disorders. Journal of the American Academy of Child and Adolescent Psychiatry, 36(Suppl.), 69S-84S.

American Psychiatric Association (APA) (1987). Diagnostic and statistical manual of mental disorders (3rd ed.revised ed.). Washington: American Psychiatric Association.

American Psychiatric Association (APA) (1994). Diagnostic and statistical manual of mental disorders (4th ed.revised ed.). Washington: American Psychiatric Association.

Bentler, P. M. (1995). EQS Structural equations modeling manual. Encino, CA: Multivariate Software.

Bernstein, G. A., \& Borchardt, C. M. (1991). Anxiety disorders of childhood and adolescence. A critical review. Journal of the American Academy of Child and Adolescent Psychiatry, 30, 519-532.

Bernstein, G. A., Borchardt, C. M., \& Perwien, A. R. (1996). Anxiety disorders in children and adolescents: a review of the past 10 years. Journal of the American Academy of Child and Adolescent Psychiatry, 35, 1110-1119.

Birmaher, B., Khetarpal S, Brent, D., Cully, M., Balach, M., Kaufman, J., \& McKenzie S, Neer (1997). The Screen for Child Anxiety Related Emotional Disorders (SCARED): scale construction and psychometric characteristics. Journal of the American Academy of Child and Adolescent Psychiatry, 36, 545-553.

Craske, M. G. (1997). Fear and anxiety in children and adolescents. Bulletin of the Menninger Clinic, 61(Suppl. A), A4-A36.

Horowitz, M. J., Wilner, N., \& Alvarez, W. (1979). Impact of Event scale: a measure of subjective stress. Psychosomatic Medicine, 41, 209-218.

LaGreca, A. M., \& Stone, W. L. (1993). Social anxiety scale for children-revised: factor structure and concurrent validity. Journal of Clinical Child Psychology, 22, 17-27.

Marsh, H. M., Balla, J. R., \& McDonald, R. P. (1988). Goodness-of-fit indexes in confirmatory factor analysis: the effect of sample size. Psychological Bulletin, 103, 391-410.

Muris P., Merckelbach H., Körver P., Meesters C. (1999a) Screening for trauma in children and adolescents: the validity of Traumatic Stress Disorder scale of the Screen for Child Anxiety Related Emotional Disorders (submitted).

Muris, P., Merckelbach, H., Mayer, B., Van Brakel, A., Thissen, S., Moulaert, V., \& Gadet, B. (1998b). The Screen for Child Anxiety Related Emotional Disorders and its relationship to traditional childhood anxiety. Journal of Behavior Therapy and Experimental Psychiatry, 29, 327-339.

Muris, P., Merckelbach, H., Schmidt, H., \& Mayer, B. (1999b). The revised version of the Screen for Child Anxiety Related Emotional Disorders (SCARED-R): Factor structure in normal children. Personality and Individual Differences, 26, 99-112.

Muris P., Merckelbach H., Van Brakel A., Mayer B. (1999c) (in press). The revised version of the Screen for Child Anxiety Related Emotional Disorders (SCARED-R): Further evidence for its reliability and validity. Anxiety Stress and Coping.

Muris, P., Merckelbach, H., Van Brakel, A., Mayer, B., \& Van Dongen, L. (1998a). The Screen for Child Anxiety Related Emotional Disorders: relationship with anxiety and depression in normal children. Personality and Individual Differences, 24, 451-456.

Muris P., Schmidt H., Merckelbach H. (1999d) (in press). The structure of specific phobia systems among children and adolescents. Behaviour Research and Therapy.

Ollendick, T. H. (1983). Reliability and validity of the Revised Fear Survey Schedule for Children (FSSC-R). Behaviour Research and Therapy, 23, 465-467.

Ollendick, T. H., Yang, B., King, N. J., Dong, Q., \& Akande, A. (1996). Fears in American, Australian, Chinese, and Nigerian children and adolescents: a cross-cultural study. Journal of Child Psychology and Psychiatry, 37, 213-220. 
Reynolds, C. R., \& Richmond, B. O. (1978). What I think and feel: a revised measure of children's manifest anxiety. Journal of Abnormal Child Psychology, 6, 271-280.

Spence, S. H. (1997). The structure of anxiety symptoms among children: a confirmatory factro analytic study. Journal of Abnormal Psychology, 106, 280-297.

Spence, S. H. (1998). A measure of anxiety symptoms among children. Behaviour Research and Therapy, 36, 545566.

Spielberger, C. D. (1973). Manual for the State-Trait Anxiety Inventory for Children. Palo Alto, CA: Consulting Psychologists Press. 